\title{
A tragic compromise on stem cell derivation
}

\author{
Jonathan D. Moreno* \\ Center for Biomedical Ethics, University of Virginia, P.O. Box 800758 U. Va. Health System, Charlottesville, VA 22908, USA
}

It appears that the official policy of the US government for federally funded studies of human embryo stem (ES) cell research will exclude the derivation of ES cells (National Institute of Health Guidelines for Research Using Human Pluripotent Stem Cells, 65 FR 69951 (November 21, 2000)). In taking this decision, the National Institutes of Health (NIH) is not to be blamed, nor should we wring our hands about the political climate that has led to it. ES cell derivation and the destruction human embryos it entails are caught in the maelstrom of the culturally divisive abortion debate that continues to fester in the United States. At the very least, however, persons who support the promise of stem cell therapy should understand the implications of this limitation and raise their voices in protest against it.

The significance of the derivation compromise has largely been lost in the popular press. Even scientifically knowledgeable journalists have not done the point justice. Yet it is known that ES cell properties depend on the methods used to derive them, particularly in their pluripotency. Worse, the multiple changes that can occur within the cells as they are cultured render their properties inconsistent and unreliable. The instability associated with their growth conditions means that ES cells cannot be simply produced centrally by a nonfederally funded source and then distributed to federally funded researchers (in order to insulate the latter from violation of regulations) without jeopardizing the cells' ability to contribute to tissue. Extended passage in culture seems to allow an accumulation of mutations that change gene expression.

Perhaps the most direct lost opportunity presented by the antiderivation policy is that of studying the process of derivation itself. The immense decade-long effort to derive and grow mouse ES cells needs to be undertaken for other mammalian species. Although that work has already begun, the time required to achieve stable ES cells from other mammals could be greatly shortened by the application of the considerable intellectual, financial, and organizational resources of the US government medical research system.

The ethical objections to public funding of stem cell derivation are almost shockingly weak. Consider one source, embryonic germ (EG) cells are derived from cadaveric fetal tissues from induced abortions. First, it has been alleged that the knowledge that an embryo stem cells could contribute to science might cause people to rationalize abortions and therefore increase their frequency. Yet there is no evidence that the frequency of abortion would be increased under these conditions, and various mechanisms have been proposed to insulate the abortion decision from the embryo donation decision, on analogy with policies for organ donation and harvesting. Second, it is argued the use of human materials remaining from abortions taints the work of medical scientists. Yet surely the surgeon involved in the transplant of an organ from a shooting victim is not thereby endorsing the murder, but rather trying to promote health and life.

As for the use of "extra" embryos remaining following fertility treatments, there is deep disagreement among religious traditions about the moral status of the embryo. Although the official Roman Catholic doctrine that full moral status must be conferred to the human embryo at conception is well known, not even all Catholic theologians subscribe to this view. And it is clear that other Christian faiths, as well as Jewish and Islamic traditions, do not accord full moral status to the early embryo. Surely the embryo must be respected as a form of human life, but it does not follow that it must be treated on a moral par with persons.

Finally, the argument that work should instead go forward using adult stem cells cannot exclude the importance of continuing on the ES cell track, nor have recent promising events demonstrated that adult stem cells possess the pluripotency of ES cells. Scientists can and must work within the constraints of policy decisions made in the political realm. In this case, however, as in the case of artificial reproduction techniques, the net result of the ban on ES cell derivation not only slows progress without good reason. It also leaves this area of science without the powerful imprimatur and guidance of public oversight, a circumstance that only compounds the tragic irony of US policy on stem cell derivation. Jonathan D. Moreno

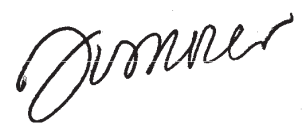

* E-mail: jdm8n@virginia.edu URL: http://www.med.virginia.edu/bioethics Fax: +804982 3971; Tel: +8049248274 

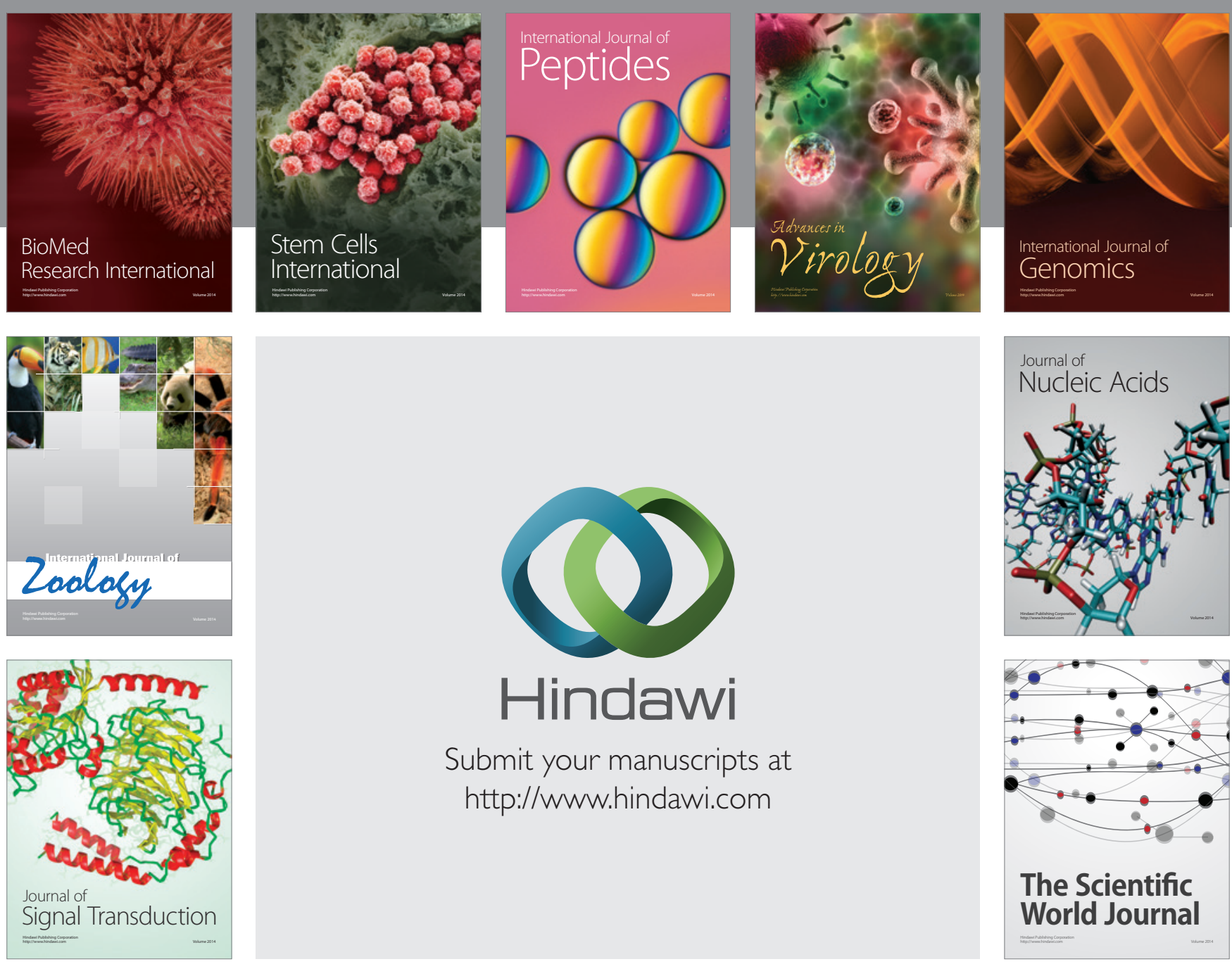

Submit your manuscripts at

http://www.hindawi.com
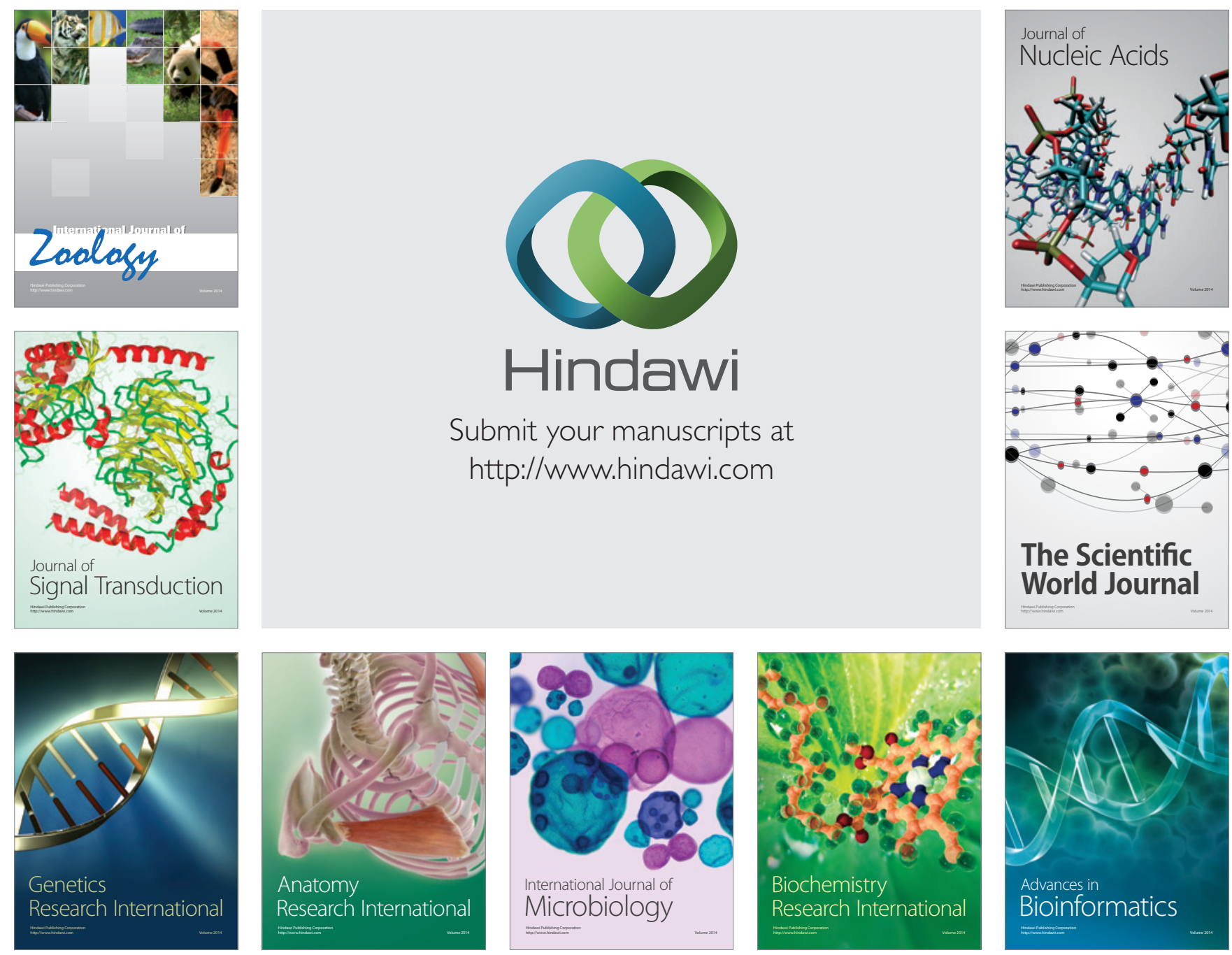

The Scientific World Journal
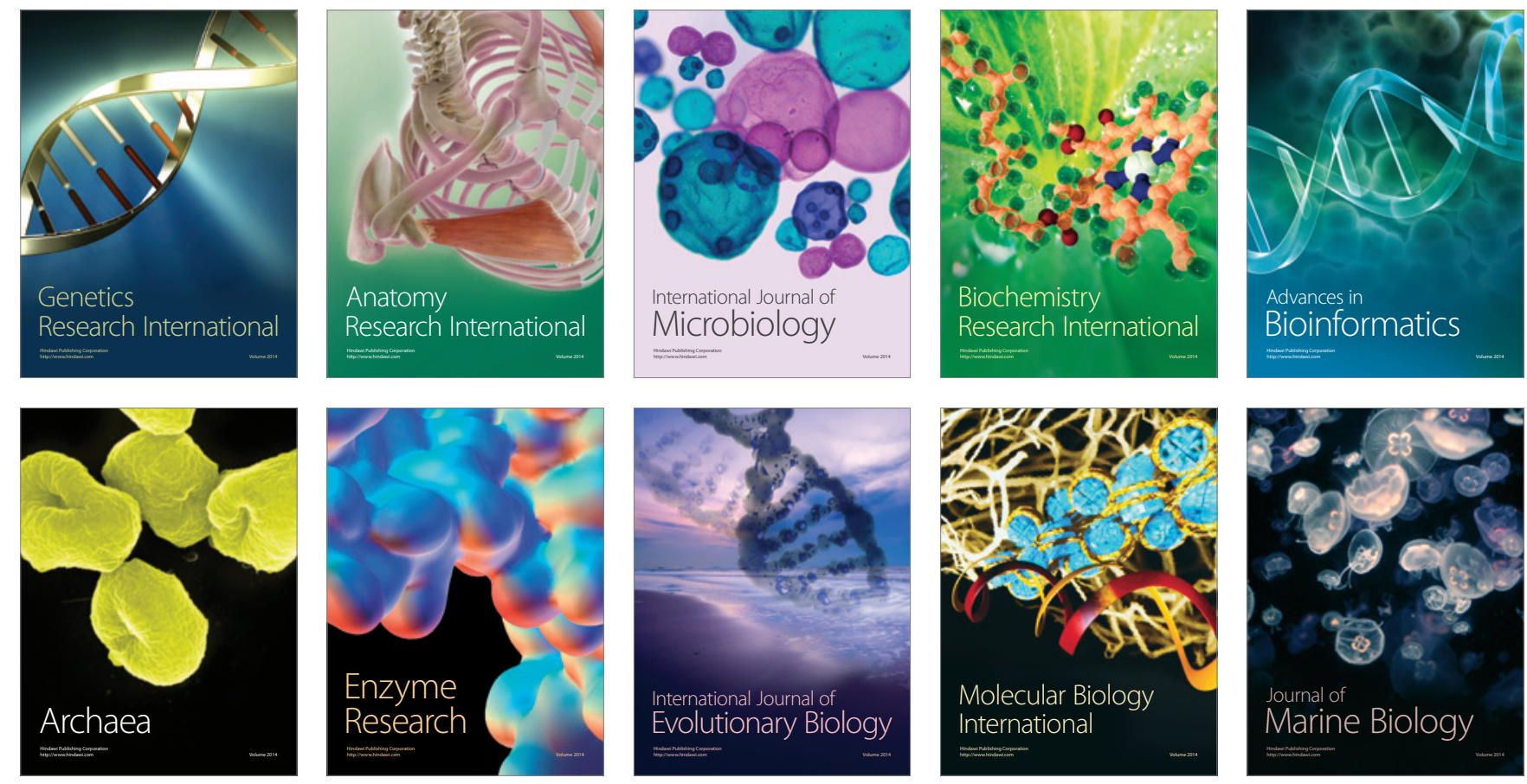